\title{
Mălina CIOCEA* \\ Alexandru CÂRLAN** \\ Prosthetic memory and post-memory: cultural encounters with the past in designing a museum
}

\begin{abstract}
This paper ${ }^{1}$ investigates the sources of representations on the communist period and the type of engagement with the past in an experiential museum, in the context of the National Network of Romanian Museums' project for a laboratory-museum of Romanian Communism. Our analysis of focus-groups in October-November 2012 explores the public's expectations in terms of museum experience and engagement with objects and the potential of an experiential museum to facilitate deliberation about the past. We use the conceptual framework of recent studies on postmemory (Hirsch, 2008) and prosthetic memory (Landsberg, 2004,2009 ) to focus on ways of building the experiential archive needed to produce prosthetic memory. We consider that such an analysis is relevant for two interconnected problems: the bidirectional relationship between a projected museum of communism and a prospective public, and the methodological insights available for investigating this relation. With regard to the first problem, this paper makes a case for treating museums as a memory device rather than a lieu de memoire and analyses the role of the museum in relation to cultural memory. With regard to the second problem, it offers an example of conducting research on prospective publics which departs from traditional marketing approaches, adopting theoretical insights and analytical categories from specific conceptualizations in the field of memory studies.
\end{abstract}

Keywords: postmemory, prosthetic memory, remembrance practices, laboratory-museum of Communism

\section{Introduction}

This paper investigates the sources of representations on the communist period and the type of engagement with the past in an experiential museum, in the context of the National Network of Romanian Museums' project for a laboratory-museum of Romanian Communism. Immediately after the fall of communism in 1989 in Romania, "museums were challenged to reinvent themselves, to renounce the blasé museum and become antidote-museums" (Bădică, 2010, p. 283). In other words, they had to reframe their production and management of significances of Communism. In the process, many of them seem to have preserved the fundamental idea behind "father-museums", that their mission was to teach their public about the truth. Against this background, the National Network developed the idea of a laboratory-

* National University of Political Studies and Public Relations, malina.ciocea@comunicare.ro.

${ }^{* *}$ National University of Political Studies and Public Relations, alex.carlan@comunicare.ro.

${ }^{1}$ This paper is the result of research developed in the project Mediere și mediatizare în memoria cinematică a comunismului românesc [Mediation and Mediatization in the Cinematic Memory of Romanian Communism] of the Laboratory Communication, Discourse, Public Issues (CODIPO) of the Centre for Research in Communication, Faculty of Communication and Public Relations, NUPSPA. 
museum, a fluid concept going against traditional museological practice and allowing negotiation of the meaning of the period. "The laboratory-museum is [...] not a temple (it does not propose or attempt to fixate a narrative for our recent history), but a place that welcomes experimentation and takes a grassroots approach towards building an institution that takes seriously its potential audience. The laboratory-museum does not attempt to transform our recent history in a museum object but aims to facilitate a process of coming to terms with this sensitive time in our past" (presentation text by Viviana Iacob, initiator of the project). The result of such a design will be a museum without a permanent exhibition, whose ownership will be claimed by no particular cultural institution.

This enterprise is not an isolated voice in the Romanian public sphere. There is vivid debate on the relationship between coming to terms with the Communist past and the integration of this experience in collective memory as a salient element of cultural identity. A map of discourses on this topic would highlight the polyphony of voices, an array of remembrance agents, overlapping images and symbols, a plurality of mechanisms and strategies for promoting various perspectives on Communism. There are, for instance, official institutional discourses (see Tismăneanu Report, the publications of the Institute for the Investigation of Communist Crimes and Memory of the Romanian Exile, the online photo collection of Communism), allegedly private discourses (Nicolae Ceaușescu's blog, web page and Facebook account), cinematic enterprises (such as Tales from the Golden Age, Mungiu et al., 2009, Nicolae Ceaușescu's Autobiography, Andrei Ujică, 2010, The Great Communist Robbery, Alexandru Solomon, 2012). These competing discourses meet in various media contexts (televised debates, press files, citizen journalism), where they negotiate versions and meanings of Communist experience in terms of historical relevance, moral responsibility and identitarian significance. We take these discourses as competing inputs for building the collective memory (Halbwachs, 1992) about Romanian communism, although they circulate in different contexts and have distinct publics.

\section{The museum as a memory dispositif}

In the context of the project for a laboratory-museum of Communism, we intend to investigate the role of the museum in building the cultural memory of this period and the politics of memory in the cultural sphere. We start from Gillian Rose's approach to discourse analysis in visual methodologies (Rose, 2001) to further differentiate between two directions in investigating how a museum's discourse impacts upon the process of building cultural memory: one dealing with sources of representation, narratives proposed for the past and intertextuality, i.e. with discursive formations and their productivity, and one dealing with institutional practices, technologies of display, issues of power and regimes of truth generating a particular engagement with the past in a museum. Although requiring different focal points in analysis (i.e. text and intertextuality vs. display technologies and engagement with the object), both directions stem from Michel Foucault and both can be subsumed to the wider approach of dispositif analysis. In relation to cultural memory, Laura Basu considers that "Dispositif analysis allows us to examine the wide range of phenomena and their relations that constitute a cultural memory, without being stalled by debates as to what is and is not a 'text'. It would mean identifying the constituent elements within a given dispositif, the relations between them, and the subject positions they bring about." (Basu, 2011, p. 35). Her approach identifies three 
main elements of memorial dispositifs: medial, temporal and political. This categorization allows the analyst to emphasize the different workings of various media in building and shaping memories (the medial element). It also points to the revolutionary changes in temporality brought about with the shifts from the 'pre-modernity' to 'modernity' to 'postmodernity', shifts that have changed the shape and structure of memory (the temporal element). Finally, it shows how cultural memory preserves the store of knowledge from which a group derives an awareness of its unity and uniqueness, inevitably generating forms of inclusion and exclusion involved with identity (the political element).

In relation to the political dimension of cultural memory, reference frameworks and interpretation schemata are needed to give knowledge about the past a common meaning for a community. Public memory builds on institutions and monuments (which are, essentially, semantic instruments that translate significances), but also on public discourses, since modern collective memory is social (a theoretical tradition stemming from Halbwachs). In this respect, we can take cultural memory as "an externalization and objectivation of memory, which is individual and communicative" (Jan Assmann, 2010, p. 122).

The contemporary interest in memory practices and devices may be taken to stem from an anxiety of contemporary culture about forgetting. Various explanations have been proposed for this memory crisis, among which the technological advancement and mediatization, which have accelerated the obsolescence of artifacts and cultural experiences alike. Paradoxically, media as instruments of remembering have been blamed for the memory amnesia of present times, because of the commodification and spectacularization of history, which might trigger the banalization of historical events. In this respect, Adorno's argument that commodification equals forgetting can be further developed to explain memory crisis through the creation of distance from historical events. In Halbwach's view of a live, collective consensual memory, storage devices are not necessary; it is mediation that invites the development of remembrance strategies and practices.

In this context, what German philosopher Hermann Lübbe called 'musealization' in the early 80 s (strategies of memorialization not restricted to museums) is an attempt to fixate cultural identity for the modern individual. Andreas Huyssen draws on Lübbe to understand musealization as a compensatory device for the "transformation of temporality in our lives" (Huyssen, 2011, p. 432), with the observation that cultural traditions are themselves affected by the same processes of change.

History museums are places where public memory is built as a symbolic and political resource both through exhibits and deliberation on the meanings of history. The significance of political events becomes visible through categorization and their "consequentiality in and for the social and ideological context" in which they are invoked (Tileagă, 2008, p. 359). The performative dimension of remembrance (Jasinski, 2001, p. 356) proposed by a history museum builds significance in the same way as rituals and ceremonies, for instance, and is partly responsible for the non-hegemonic character of public memory (because both the objects and the agents of remembrance are submitted to debate and critical discussion).

Forms of social activism can develop from this debate, and this ties in with the mission that history museums have assumed in time: to investigate historical evolutions and ideological representations of events. In the case of a museum of Communism, the management of these representations has to take into account several constraints: first, it needs to address the issue of its past as an instrument of official propaganda during Communism (Bădică, 2010, p. 275); second, it has to reflect competing discourses about the Communist experience in the 
public sphere; third, to stimulate dialogue among various such discourses. The social memory of Communism is to be found in conflicting, "lay" and scientific interpretive frameworks alike (Tileagă, 2012a). Essentially, history museums present an elitist version of the communist past, a fact which is also true of public political discourse (Tileagă, 2012b). On the other hand, studies on people's attitudes toward Communism show an array of perspectives which vary widely with age, level of education and social status (see IICMER report, 2012).

The museum as a storage device against forgetting is an artificial construction in that it introduces categories, chronology and causal interdependence where there is little or none. This recreation of history is, however, constitutive of remembrance as discourse about the past, in much the same way representation of reality is constitutively different from reality. "[O]ur contemporary memory crisis with its attendant rash of commemorative acts may be based less on the production of synthetic memories that the migration of history into advertising and the nostalgia industry seems to affect and more on the paradoxical assumptions embedded within the methodology of curatorship and the ideology of the collection" (Boyer, 2011, p. 379).

In the light of these theoretical considerations, the project of a museum of Communism seems to be confined to two extremes: one would be to adopt a stance similar to Adorno's formula "coming to terms with the past", and admit that such a museum assumes a specific mission (the truth about Communism), a certain epistemological authority and ideological role, which would encourage a museum concept along the very lines criticized by Boyer. But such a project, normatively oriented, might collide with the expectations of a younger generation, for whom issues of guilt and responsibility, crucial to Adorno's argument, might not be at stake. The other extreme would be the contemporary experiential museum, focused on prosthetic re-living (as conceptualized by Alison Landsberg), with no claim for epistemological or ideological authority, proposing an affectionate and even entertaining engagement with the past, and favoring a decidedly deliberative stance, where the visitor freely negotiates the meaning of history throughout the museum experience. The risk of such a project, at odds with a traditional view of the museum, would be the dissolution of any unitary meaning of history and the perceived "trivialization" of the experiences of previous generations. Both options can assume the mission of the antidote museum (Bădică, 2010) and both can propose an exhibiting regime of an elitist or broad appeal. The success of any of them is dependent on assumptions about how the public connects with the previous generation and what kind of place they allow for museums in this process. The analytical framework for investigating the relationship between the young generation (probably disconnected from the past) and previous generations is developed in the following section.

\section{Post-memory and prosthetic memory: two approaches to generational gap in memory studies}

Two concepts describing the mediations at stake in the progress from communicative memory to cultural memory are particularly apt for understanding how young generations can appropriate the past into their memories. Although different in scope, explicative power and theoretical rooting, both concepts investigate the works of memory within a generational gap and the dynamics between private and public forms of memory. The differences in understanding the interplay between memory and identity in these two approaches render them as valuable starting points in the elaboration of a museum project. 
The concept of postmemory is a very important analytical contribution proposed by Marianne Hirsch in the field of holocaust studies $(2001,2008)$. The concept describes specifically the bridging of a generational gap between the "generation before", those who experienced cultural or collective trauma, and the "generation after" or "the second generation", who "remember only by means of the stories, images, and behaviors among which they grew up" (Hirsch, 2008, p. 107). According to Hirsch, characteristic of this type of remembering is that "these experiences were transmitted to them so deeply and affectively as to seem to constitute memories in their own right. Postmemory's connection to the past is thus not actually mediated by recall, but by imaginative investment, projection, and creation. To grow up with such overwhelming inherited memories, to be dominated by narratives that preceded one's birth or one's consciousness, is to risk having one's own stories and experiences displaced, even evacuated, by those of a previous generation. It is to be shaped, however indirectly, by traumatic events that still defy narrative reconstruction and exceed comprehension. These events happened in the past, but their effects continue into the present. This is $(\ldots)$ the experience of postmemory and the process of its generation." (Hirsch, 2008, p. 107) The consequence of such a relation between past and present is the maintenance and perpetuation of a living connection between generations, which fosters group identity and defines relations with outgroup. In this context, photography has a key role - and in particular family photographs, since "as a medium of postmemory clarifies the connection between familial and affiliative postmemory and the mechanisms by which public archives and institutions have been able both to reembody and to reindividualize "cultural/archival" memory." (Hirsch, 2008, p. 115). In this sense, the indexical quality of photography makes it a central piece of a museum's dispositif, linking representations and forms of engagement with processes of identity formation.

Hirsch recognizes the multiple problematic aspects of her approach. Whether postmemory is limited to the "intimate embodied space of the family" or can extend to more distant observers and participants outside the frame of intergenerational exchange, remains undecided. Associated with this aspect is the confinement of postmemory only to victims of trauma - which although plausible, doesn't necessarily exclude the possibility that bystanders and perpetrators could take part in this structure of intergenerational transmission of trauma. She remains optimistic about the inclusive possibilities of post-memory, although some prerequisites are still implicit in this engagement with postmemorial processes: "Postmemorial work (...) strives to reactivate and reembody more distant social/national and archival/cultural memorial structures by reinvesting them with resonant individual and familial forms of mediation and aesthetic expression. Thus less-directly affected participants can become engaged in the generation of postmemory, which can thus persist even after all participants and even their familial descendants are gone." (Hirsch, 2008, p. 111) It's unclear, in this fragment, what are the prerequisites for postmemorial work to be effective, and its limits in relation to total strangers, but certain criteria of belonging seem to be required in order to be part of postmemorial processes: a symbolic belonging to the group of victims or a connection with the events.

Different questions arise when the concept of postmemory is exported from holocaust studies in other fields, such as post-communism, where the dynamics of memory produce a mode of remembering totally impossible in the original framework: that of nostalgic remembering. Such a conceptual relocation might be risky since "postmemory is not a movement, method, or idea; (...) [but] a structure of inter- and trans-generational transmission of traumatic knowledge and experience. It is a consequence of traumatic recall but (unlike posttraumatic stress disorder) at a generational remove" (Hirsch, 2008, p. 106), Yet, while at odds 
with the traumatic experience, nostalgic remembering seems to share with postmemory the affectionate register, the imaginative investment, projection, and creation of memories, the multiple mediations that produce affiliation between generations and reinforce a sense of continuity within community's identity.

Alison Landsberg defines prosthetic memories as particular forms of public cultural memory (the memory of a past that has not been directly experienced) that "emerge at the interface between a person and a historical narrative about the past, at an experiential site such as a movie theater or museum. In this moment of contact, an experience occurs through which a person sutures him or herself into a larger historical narrative. In this process, the person does not simply learn about the past intellectually, but takes on a more personal, deeply felt memory of a past event through which he or she did not live in the traditional sense." (Landsberg, 2009, p. 222) The domain of this concept comprises the situations when "links between parents and children, and most significantly, between individual persons and community kinship ties - were broken, and alternative methods for transmission and dissemination of memories were required." (Landsberg, 2004, p. 2)

Landsberg's approach is circumscribed in a mediological perspective: prosthetic memory is a particular case of "prosthetic extensions", a concept McLuhan takes over from E.T. Hall to describe the functioning of communication technologies. The term is not inherently positive or negative. Invoking Krackauer and Benjamin, Landsberg puts forth the argument that despite their inauthenticity, prosthetic memories are personal memories, since they result from engaged and experientially oriented encounters with the mass media's various technologies of memory. These confrontations are sensorial and the negotiation of meaning is made by reference not only to the artistic object itself (which takes part in this negotiation with its own indexicality), but with the individual's prior experiences. Moreover, prosthetic memory targets a public past, not a single individual's or group's possession, although its sources can be private. In her works $(2004,2009)$, Alison Landsberg claims that such prosthetic memories allow for a new radical politics of empathy. Drawing on a phenomenological account, she discusses empathy in contrast to sympathy, concluding that, "unlike sympathy, empathy does not depend on a 'natural' affinity or some kind of essential underlying connection between the two subjects. Empathy, in this account, is a way of understanding the other without having actually undergone the other's experiences. Empathy recognizes the alterity of identification and the necessity of negotiating distances and is therefore essential to any ethical relation to the other" (Landsberg, 2004, p. 24). In this approach, empathy is not only aimed at understanding the other, but a way of "inhabiting other people's memories as other people's memories and thereby respecting and recognizing difference" (Landsberg, 2004, p. 24). Opposing Halbwachs' view, Landsberg shows that in contrast with collective memory, which serves to reinforce and naturalize a group's identity, prosthetic memories are not the property of a single group, but allow collective horizons of experience, since the pasts that prosthetic memories open up are available to individuals across racial or ethnic lines, across cleavages between victims and perpetrators. In summary, prosthetic memories are not natural or authentic, but are personal, because they suppose a mediated experience of the event, they are incorporated, just like an artificial limb, are interchangeable in their quality of goods for symbolic consumption, and build not only subjectivities, but mediated collective identifications, opening the way towards the construction of counterhegemonic public spheres. They are also an argument that "affective power might be mobilized to have a similar kind of political potential as conceptual power" (Landsberg, 2004, p. 4). 
These two approaches to memory share significant features, but also differ relevantly. They both target a generational rupture and propose ways of reconnecting with one group's identity. They both have a marked mediated character (family photographs, in the case of post-memory, media fictions and experiential museums in the case of post-memory), and propose a type of engagement with the past, which is mainly affective and sensorial. But postmemory is part of the private sphere symbolized by the family photograph, while prosthetic memory has "the commodified nature of mass cultural representations that makes them so widely available to people who live in different places and hail from different backgrounds, races, and classes, and that (...) precludes them from being the private property of a particular group". (Landsberg, 2009, p. 222). While in postmemory the implicit finality (working as an organizing principle) is represented by reconciliation within an already constituted group (by coming to terms with a traumatic past), prosthetic memories, as implicit finality, transcend group identities towards new forms of solidarity. We consider this to be the case due to the relationship with identity that is characteristic of each of the two forms of memory: while post-memory results in a consolidation of group identity (by means of traumatic re-living, through sympathy and multiple mediations of familial artifacts), prosthetic memories lead to a progressive, cosmopolitan politics, based on empathy. Ultimately, the essential difference between the two approaches can be better understood if one conceptualizes this memorial transmissions as a communication process and focuses on the position of the receiver in this process: in the case of post-memory, the receiver is included from the very beginning, she is already a part of the community whose identity is reinforced through processes of remembering, while in the case of prosthetic memory, the receiver is allegedly an outsider who is to be included, through empathy, in a community that doesn't necessary precede the process of prosthetic remembering, but is constituted through it. In our view, the two concepts can be conceived as the extremes of a scale describing the possible approaches to conceptualizing a re-appropriation of the past by the generation after, and can be systematically linked with the design of a museum as a memory device.

\section{Empirical Research}

Taking the museum as a memory device, we attempt to investigate how remembrance is produced through engagement with objects/artifacts in the museum and to discuss the potential of an experiential museum to facilitate deliberation about the past.

To this end, we conducted four focus groups in Bucharest, Iași and Sibiu in October-November 2012. The participants were relatively cosmopolitan, educated, with rich museum experience. We selected people in the 20-29 age group, because they do not have significant personal experiences about Communism and, at the same time, they are one of the main target groups of the future laboratory-museum of Communism. The focus group in Iași was conducted at the National Museum Complex Moldova on the youngest participants (mean age 19), with background education in humanities and arts. In Sibiu the focus group took place at the National Museum Complex ASTRA; the participants were older (mean age 24) and had various backgrounds, from humanities to economic studies. In Bucharest the focus groups took place in a neutral setting, with people aged 20-29, from various educational backgrounds. All participants in the focus-groups visit exhibitions/museums 2-4 times a year, which places 
them higher than the national average; participants in Bucharest are the most active visitors in museums (they request an audioguide, touch the objects when given the possibility, etc.).

We started our investigation from the following research questions:

1. What type of experiential engagement in a museum is likely to generate the public's empathy towards the otherness of the past? This question seeks to investigate the public's expectations in terms of museum experience and engagement with objects, in order to find out whether museum experience is compatible with a model of prosthetic memory.

2. How can an experiential museum facilitate deliberation about the past? There is a twoway dynamics between present and past in the process of deliberation: from an (undisputed/known) past towards an evaluation of the museum concept or from the recognition of the concept towards a re-evaluation of the visitors' personal understanding of the communist period. Our previous research (Ciocea, Cârlan, 2013) suggests that the younger generation are more likely to adopt a fallible position in respect with the past and, as a consequence, more willing to reevaluate their representation of the past as a result of interaction with mediated memories. The older generation tend to take their own unmediated memories of Communism as a point of reference for evaluating the truthfulness of the mediated memories in the present. For the purpose of this study, we will investigate how the museum experience is evaluated in relation with a personal experiential archive (Landsberg) and general public knowledge of the period. Finally, we want to see which direction is the more salient: from the past to the present or the other way round?

\section{a. Experiential engagement}

In the case of the first research question, the relevant section in the focus group guide comprised questions about museum experience in general and prominent memories of museum visits, and allowed respondents to highlight desirable changes in museum design, for a positive overall experience. One question in particular asked participants to imagine an interaction with an artifact in a museum, to allow us to understand possible cognitive/affective engagement. Direct engagement with the object, sensorial experience, and elicitation of empathy are characteristic of prosthetic remembrance, which is enabled by a fluid, non-normative museum concept. However, this can only aim at fragmented knowledge of the past.

Many of our respondents had rich cosmopolitan experiences with modern museums, and consequently projected a museum with modern installations and hands-on interactions with exhibits. However, there seems to be an implicit understanding that museums back home would hardly encourage modern installations or sensorial experiences. Asked to imagine how he would interact with an interesting exhibit, one respondent said: "The traditional please do not touch. It is quite a paradox that the museum offers authentic objects and the possibility for direct contact with relics from various epochs, but at the same time there is this restriction - eyes only." (FG4, B3)

Not all participants equate direct interaction with artifacts with a better understanding of the period; the novelty of the museum experience does not necessarily amount to increased knowledge or empathy towards the people who lived through those times. See, for instance, an empathic experience versus a skeptical one: "Apart from history, that particular museum [The Holocaust Museum in Berlin] shows brilliant ideas that make you feel what the Jews have felt throughout history (...) I loved the intimacy (...) I had the feeling that I managed to un- 
derstand what some people felt at a certain time - which is very important, or so it seems to me. They managed to transport you back into that state" (FG1, R., italics added)/[What would you include in the museum?] "I would look for various objects from that time in factories. Furniture bearing a registration number ... But [separate objects] cannot create an image in the museum about everyday life back then. Plus, it does not seem normal to me to bring everything back 20 years before, because things have evolved and we cannot live in the past." (FG3, F.) The first respondent points to empathy as a means of building knowledge about the period. The employment of categories of affect in the answer to the questions How did people who lived back then experience the period? What was it like to live at that time? points to the relational and empathic disposition towards the past experience that is central to the concept of prosthetic memory. The second respondent highlights one of the risks of prosthetic remembrance, encouraging nostalgia, seen by some analysts as a distortion of the meanings of the past. We also have respondents that approach the museum experience cognitively. For instance, to the questions What is this museum about? What are the relevant facts about the field?, one of them said: "That was a museum you learned something from ... They had various installations that explained how the water erodes the rocks and you could play with the tap to see the water run. And they had this other installation that simulated an earthquake in Japan in the '70s. They made everything so that you could understand, they did not just give you the information. And there were children everywhere." (FG1, I.)

Many participants would choose banal, obsolete objects for the museum (soda makers, pioneers' cravats, wedding pictures, cars, queues in front of delis). One participant said: "for instance, I could find out a lot [about Communism] from antique fairs where they sell insignia, books about the party [...] Each tells a story: look, this is the money they used back then! [...][T] he book from 1982 [with the dedication] 'from your party comrade"' (FG2, A.) This choice of experiencing and engaging with objects is indicative of this potential public's preference for modern museum experiences. On the other hand, those who insist on the educational mission of the museum would rather include objects indicative of trauma: objects bearing the official insignia, documentaries, witness reports, pictures from the revolution and collectivization, prisons. In general, preference for banal objects and everyday life points to an experiential engagement of empathetic nature and personal involvement in the reconstruction of the meaning of the objects displayed. Some participants, however, point to the limits of personal experience: the museum should contain "the truth about communism. Something that should change that poor perception I have. I still associate communism with those huge queues, with the fact that we could not leave unless we had written permission, with the fact that you could only find chocolate and sweets in Bucharest, that I had to say Father Frost, not Santa Claus, that we could not play carols" (FG 3, W.).

The comments received about museum experience and interaction with objects are consistent with the findings from the first stage of our research. Using questionnaires to investigate the potential public of a laboratory-museum of communism, Zbuchea and Ivan (2014) were able to identify two types of visitors. Those who are selective visitors have an interest in specific exhibits, are less appreciative of interactive experiences, return to revisit the exhibition and participate in the museum's educational programs. The broad-image visitors are interested in interactivity and overall experience of the museum visit: they take advantage of all facilities offered by the museum (they read all the labels, use the audio-guide and the touchscreens, and are interested in the documentaries). An evaluation such as the following is illustrative of a selective visitor: "I like museums that have large open spaces and the ex- 
hibits are not cluttered and I can walk around and see something which attracts my attention. And leave the museum with the remembrance of a new artist I did not know about. And then search information about him. I do not seek to find out everything in the museum about that person. I can find out something, an anecdote, something to raise my interest - but I will not have the information forced upon me. I prefer to leave [the museum] with some sort of curiosity" (FG1, K.). On the other hand, participant I. speaks about a certain museum in Romania in terms of broad-image: a museum "which I think has segments that are really interesting for foreigners, who are given something to see; but it also has study and reading rooms, spaces for events or which present current affairs. And it is these rooms that bring people back to the museum constantly" (FG1, I.).

Although it is difficult to equate broad-image visitors' experience with prosthetic remembrance, it is true that such a visitor is quite likely to engage empathetically with the past at a sensorial level. On the other hand, both selective and broad-image visitors can challenge a museum's attempt at ideological authority and can engage in deliberations about the meaning of the historical period presented in the museum.

\section{b. Deliberation in the museum}

Our second research question sought to understand how an experiential museum can facilitate deliberation about the past. How do respondents evaluate the role of the museum? Is the museum experience evaluated in relation with a personal experiential archive or the general public knowledge of the period? We also wanted to see whether respondents are eager to reevaluate their representation of the past.

In our grid, we investigated: the participants' interest for Communism, the way they project the potential public of the museum, the exhibits that should be included in the museum. We also wanted to find out which themes about the period are most salient in the public sphere, which are the actors participating in the debate and which are the most significant symbolic resources on the meaning of Communism.

In the participants' opinion, current perceptions about Communism are fragmented and authority sources, dispersed ("There is a lot of talk because nothing is known. Each has a piece of the puzzle, but there is no bigger picture" - FG1, I. One (young) respondent pointed to message overload in the public sphere: "We are saturated with communism. People do not even know their genealogy and they are requested to know history" (FG4, T.)

Except recent cinematography (especially Tales from the Golden Age), the symbolic resources of remembrance are stereotypes and, sometimes, individual experience. Family or group resources (indicative of post-memory) and official memory (textbooks, school curricula) are not often invoked in the interaction.

Narratives of personal experiences are naturally rare (given the age of participants) and the experiential archives tend to be nostalgic and cliché-ridden (probably because what is remembered is early childhood): "my first reaction is rejection. I am from Târgu-Jiu and I associate communism with the image of shops that were always empty. On the shelves you could probably find a loaf of bread, a bottle of cooking oil and a packet of flour. I adored going to Bucharest because you could find sweets there and I always returned with supplies. The second thing that I remember is whispering, rather than talking out loud, the fact that the local police came to my door because grandfather taught me Christmas carols, but I also remember people's elation when the Revolutions started" (FG3, D.). 
In one instance, a participant introduced a "validity hierarchy" in personal versus official archives: the media and the school "might appear a less risky source than the stories told by grandparents. Well, live experiences are good as well, but there is always the risk we might run into unjustified nostalgia." (FG1, I) For participants, it is the significant absences, rather than the recurrent representations about the period, that are most relevant for attributing a meaning of the period: "important information is left in the dark, such as, what was happening then $[\ldots]$ to people who ended up in prison, or to those who wanted to go abroad, or what happened to the information that reached us, how filtered it was" (FG4, W).

We can notice that the participants are open towards forms of prosthetic memory, rather than postmemory. The previous generation's experiences seem to have been accidentally conveyed to the generation after. In one particular instance, in the focus group with younger respondents (mean age 19), participants expressed an interest in the period that we could attribute to nostalgic remembrance, which does not stem from personal or parental memories, but probably from media culture (Moderator: Do you have a curiosity about that period? F1: Of course, it was fascinating! - FG4). On the other hand, there is tension between these authority sources (F: It was better in Ceaușescu's tine! Everybody says so!/B3: How old were you in 1989? You were not even born!/F: No, I was not./B: I do not know what to say .... as F. said, everybody feels it was better in the past. Each generation believes this."

Few participants invoke traumatic experiences of close family; the rare personal insights are either nostalgic, or detached: "I remember a lot, but I am now at peace, I have no trauma from the past" (FG1, M); (Moderator: Who would be interested in the museum? "my parents' generation and older people who are not at peace with themselves, have not fought all their battles and then I see them living that present, rather than this one" (FG1, I.).

This fragmentation and lack of imaginative investment have led to a cognitive approach to the role of the museum in the debate on Communism: the projected museum should correct false representations and teach the young people and the foreigners about the true meaning: "I believe that a growing number of people [...] no longer have any fixed point about the period and as a consequence they have no interest in it" (FG1, I.). When asked who should establish a museum of Communism, participants invoke the argument of authority: "somebody who could do something objective. For instance, just like nowadays they summon various commissions, they could form a commission of people who lived back then or who were part of ruling classes, but also of people our age, who could build a more commercial side to this museum, because this is needed as well. Maybe at the price of slight misrepresentation, for commercial purposes" (FG3, M.)

Many respondents take a critical distance towards the role of the museum as a facilitator of understanding, rising, in part, from distrust in any attempt at fixing the meaning of the period, and, on the other, from the fluid, non-normative concept behind the projected museum (Moderator: Who would be interested in the museum? "Nostalgic people, although the people who lived back then might not be very interested. The middle-aged people would visit it because they would be curious to see symbols their parents talked about. Adolescents would be curios, but not very interested, it is not something specific to their age, maybe later they grow aware that they learned about communism in history classes. I know there was an optional subject on the history of communism in high-school, some years ago. So, at one moment, there were attempts at presenting facts ... Yet these are somebody's subjective opinions, if we talk from historians' perspective, because eventually history is made by historians FG3, B). 
On the other hand, the museum still has a lot of legitimacy as a facilitator of engagement with the past and as a depository of the truth. In participants' opinion, coming to terms with the past is only possible if the truth is revealed: "I would invite everyone at the museum, because a museum works with exact data, and because this is an unclear period, everything must be in good order, and this depends on custodians, who need to be very well prepared and research the topic" (FG4, M.). In this case, the relationship with the past is mediated by knowledge and presentation of facts: "we do not have an opinion, we have just taken over other people's opinions. If you see, you will have an opinion yourself" (FG4, M.). A fluid concept would work best when it is difficult to fix the meaning of the period:"I believe that all of those who added a little something in time should now come together for this museum [...] Each knows a piece [...] And something might come out of this. And every three years, you should make another museum" - FG1, M.).

Paradoxically, although the participants turn to those who have experienced Communism directly to get informed about the past, there is tension between the implicit trust in the knowledge resources and distrust in the validity of their experience/interpretation: "[...] [O]nly those who lived through both times can make a comparison. We can only imagine. There is a difference between imagining and living" (FG4, A.)

Our analysis confirms the findings of Zbuchea and Ivan (2015), that expectations of museum goers vary widely: from interest in micro-phenomena (such as the daily lives of people in Communism) especially in younger people who did not experience the period directly, to macro-phenomena (deriving meaning from the systemic effects of Communism on Romanian society). We can attribute this latter interest to the high level of education of people who participated in the focus, but also to their expectation that the museum should educate the public.

\section{Concluding remarks}

To conclude, we can notice a paradoxical attitude of participants in the focus groups: they want a modern, non-normative reception experience (encapsulated in the systematic preference for an experiential museum, a desire for affective engagement with the past and emotional identification through the museum), but have a "traditional" perspective on the mission of the museum, expressed in a cognitive register: a museum should show what the period was like, should document the past, serve as evidence, correct perspectives, educate and teach. In other words, the museum experience anticipated or desired by the public can be understood in terms of prosthetic memory, but the aims of such a project (the design of laboratory-museum) are not assumed in all its radicalism (no final version about the past, no institutional ownership).

We may interpret this paradox not necessarily as an inconsistency in the public, but as a reflection of the visitors' reticence to clearly differentiate between sensorial and affective areas of memory, on the one hand, and cognitive areas, on the other, a problematic dichotomy promoted by the theories of mediated memory and post-memory. There is indeed a risk that an over-emphasis on experientiality might in fact block deliberation, because it does not encourage the critical distance required for the visitor's objectified evaluation. Moreover, the absence of a permanent exhibition, as envisaged by the museum's project, means a lack of official perspective on the communist period, by the institutional infrastructure that governs 
the museum. Aside from the clash with the traditional view of the museum revealed by focus groups, such a shortcoming is problematic for two reasons: because it pushes the final stage of the process of "coming to terms with the past" towards an indefinite resolution and, furthermore, helps maintain the status quo of the official perspective on communist history, encapsulated, for instance, in Tismăneanu Report.

A different conclusion regards the productivity of approaches stemming from memory studies and cultural analysis to understand and initiate research about museum experience and museum publics, a trend of research which typically follows a rather instrumental, marketing-oriented approach. In this regard, the relevant differences in relation to group identity and cultural memory, emphasized by the comparative analysis of postmemory and prosthetic memory, allow operationalizable insights for the research of museums' design and museums' publics, going beyond the instrumental approach specific to marketing research.

\section{References}

1. Assmann, J. (2010). Globalization, Universalism, and the Erosion of Cultural Memory. In A. Assmann, \& S. Conrad. (Eds.). Memory in a global age: discourses, practices and trajectories. Houndmills, Basingstoke (pp. 121-137). UK: Palgrave Macmillan.

2. Bădică, S. (2010). Same exhibitions, different labels? Romanian national museums and the fall of communism. In S.J Knell., P.Aronsson, A.Amundsen. (Eds.). National Museums. New Studies from Around the World (pp.272-289). London: Routledge.

3. Basu, L. (2011). Memory dispositifs and national identities: The case of Ned Kelly. Memory Studies, $4(1), 33-41$.

4. Boyer, M. C. (2011). The city of collective memory: its historical imagery and architectural entertainments. In J. K. Olick, V. Vinitzky-Seroussi \& D. Levy. (Eds.). The collective memory reader (pp. 378381). Oxford: Oxford University Press.

5. Cârlan, I. A., Ciocea, M. (2013). Mémoire prothétique du communisme. Le film L'Autobiographie de Nicolae Ceaușescu de Andrei Ujică et sa réception dans les médias. In I. Drăgan, J.F. Tétu, P. Ştefănescu, N. Pélissier, L. Idjeraoui-Ravez, L. (Eds.). Traces, Mémoire et Communication (pp. 69-80). București: Editura Universității din București.

6. Halbwachs, M. (1992). On collective memory. Chicago: University of Chicago Press.

7. Hirsch, M. (2001). Surviving images: Holocaust photographs and the work of postmemory. The Yale Journal of Criticism. 14(1), 5-37.

8. Hirsch, M. (2008). The generation of postmemory. Poetics Today, 29(1), 103-128.

9. Huyssen, A. (2011). Present pasts: Media, politics, amnesia. In J. K. Olick, V. Vinitzky-Seroussi \& D. Levy. (Eds.). The collective memory reader (pp. 430-436). Oxford: Oxford University Press.

10. Iacob, V. (2012). The laboratory-museum: Explorations for a museum of the communist period in Romania. Retrieved May, 15, 2015, from http://www.europeanmuseumacademy.eu/4/upload/1_the_laboratory_museum.pdf.

11. IICCMER (2012). Atitudini și opinii despre regimul comunist din România. Sondaj de opinie publică. Retrieved May, 15, 2015, from http://www.iiccr.ro/pdf/ro/sondaj/raport_iiccmer.pdf.

12. Jasinsky, J. (2001). Memory. In J. Jasinsky. (ed.). Sourcebook on Rhetoric: Key Concepts in Contemporary Rhetorical Studies (pp. 355-363). London, New Delhi: Thousand Oaks, Sage Publications.

13. Landsberg, A. (2003). Prosthetic Memory: The Ethics and Politics of Memory in an Age of Mass Culture. In P. Grainge. (ed.). Memory and Popular Film (pp. 144-161). Manchester: Manchester University Press.

14. Landsberg, A. (2004). Prosthetic Memory: The Transformation of American Remembrance in the Age of Mass Culture. New York: Columbia University Press. 
15. Landsberg, A. (2009). Memory, empathy, and the politics of identification. International Journal of Politics, Culture and Society, IJPS, 22 (2), 221-229.

16. Presidential Commission for the Study of Communist Dictatorship in Romania (Tismăneanu Report). (2007). Final Report of the Presidential Commission for the Study of Communist Dictatorship in Romania. Humanitas, 2007.

17. Rose, G. (2001). Visual methodologies: An introduction to researching with visual materials. Sage.

18. Tileagă, C. (2008). What is a revolution? National commemoration, collective memory and managing authenticity in the representation of a political event. Discourse \& Society, 19(3), 359-382.

19. Tileagă, C. (2012a). Communism and the meaning of social memory: towards a critical-interpretive approach. Integrative Physiological and Behavioral Science. 46(4), 475-492.

20. Tileagă, C. (2012b). Communism in retrospect: The rhetoric of historical representation and writing the collective memory of recent past. Memory Studies. 10(4), 462-478.

21. Zbuchea, A., and Ivan, L. (2014). Le public d'un musée du communisme et l'intérêt des visiteurs pour la période communiste. In Proceedings of the French-Romanian colloque: Actualité scientifique en communication des organisations: questionner les nouveaux enjeux, problématiques et pratiques, forthcoming.

22. Zbuchea, A., and Ivan, L. (2015). Painting Shades of Gray: How to Communicate the History of Communism in Museums. This issue. 